\title{
Comunicação e consumo da cidade: entre espaços construídos e espaços vividos ${ }^{1}$
}

Communication and consumption of the city: between constructed spaces and living spaces

\section{Tânia Cezar Hoff}

Professora titular do PPGCOM-ESPM

\author{
Adriana Lima Oliveira \\ Doutoranda do PPGCOM-ESPM
}

Artigo submetido em 21 de Agosto de 2019 Artigo aceito em 27 de Outubro de 2019

\section{RESUMO}

Abordamos, neste artigo, o consumo da cidade a partir da produção de sentidos e de discursos presentes em projetos de reurbanização da região central da cidade de São Paulo, lugar que propicia diálogos, debates e embates característicos do nosso espaço-tempo histórico e que nos permite descortinar os discursos institucionalizados sobre áreas urbanas de interesse de várias ordens. Definimos como questão a ser debatida a produção de sentidos sobre a cidade de São Paulo, notadamente aquela promovida no âmbito de projetos de reurbanização, bem como as concepções de cidade que justificam intervenção no centro desta metrópole brasileira. Para tanto, o corpus a ser analisado é formado por três propostas de reurbanização na região central da cidade de São Paulo: Projeto Nova Luz, 2011; Projeto Centro Novo, 2017; e Projeto Campos Elísios Vivo, 2018. Tendo como principal inspiração teórico-metodológica a análise de discurso de linha

\footnotetext{
1 Este artigo é uma versão modificada do trabalho apresentado ao Grupo de Trabalho "Consumos e processos de comunicação”, do XXVIII Encontro Anual da Compós, Pontifícia Universidade Católica do Rio Grande do Sul, Porto Alegre - RS, 11 a 14 de junho de 2019.
}

Dossiê Espaço Urbano e Imaginação Cultural - https://revistaecopos.eco.ufrj.br/

ISSN 2175-8689 - v. 22, n. 3, 2019

DOI: $10.29146 /$ eco-pos.v22i3.27414 
francesa, mobilizamos estudiosos do campo da comunicação, dos estudos do consumo e da cidade que fundamentam teoricamente nossas reflexões.

PALAVRAS-CHAVE: Comunicação e consumo; Discurso; Cidade.

\section{ABSTRACT}

In this article, we discuss the consumption of the city through the production of meaning and discourses about urban redevelopment projects in the central region of the city of São Paulo, a place that generates dialogues, debates and disputes towards our historical space-time and allows us to uncover institutionalized discourses on urban areas of interest in different levels. We define the production of meanings about the city as a debated question, especially the ones promoted in the scope of urban redevelopment projects, and the conceptions that justify the interventions at the center of this Brazilian metropolis. For this, the corpus to be analyzed is formed by three intervention proposals in the central region of the city of São Paulo: Project Nova Luz, 2011; Project Centro Novo, 2017; and the Campos Elíseos Vivo project, 2018. Having French Discourse Analysis as our main theoretical-methodological inspiration, we mobilized scholars from the field of communication, from studies of consumption, and from the city that based our reflections theoretically.

KEYWORDS: Communication and consumption; Discourse; City.

\section{RESUMEN}

En este artículo, abordamos el consumo de la ciudad a partir de la producción de significados y discursos presentes en proyectos de reurbanización de la región central de la ciudad de São Paulo, un lugar que proporciona diálogos, debates y enfrentamientos característicos de nuestro espacio-tiempo histórico y nos permite. desvelar los discursos institucionalizados sobre áreas urbanas de interés de varios órdenes. Definimos como una cuestión a debatir la producción de significados sobre la ciudad de São Paulo, en particular la que se promueve dentro del alcance de los proyectos de reurbanización, así como las concepciones de la ciudad que justifican la intervención en el centro de esta metrópolis brasileña. Para este fin, el corpus a analizar consiste en tres propuestas de reurbanización en la región central de la ciudad de São Paulo: Projeto Nova Luz, 2011; Proyecto Centro Novo, 2017; y el proyecto Campos Elísios Vivo, 2018. Teniendo como principal inspiración teórico-metodológica el análisis del discurso francófono, movilizamos a académicos del campo de la comunicación, los estudios del consumidor y la ciudad que subyacen teóricamente a nuestras reflexiones.

PALABRAS-CLAVE: Comunicación y consumo; Discurso; Ciudad.

\section{Introdução}

Dossiê Espaço Urbano e Imaginação Cultural - https://revistaecopos.eco.ufrj.br/

ISSN 2175-8689 - v. 22, n. 3, 2019

DOI: $10.29146 /$ eco-pos.v22i3.27414 
A cidade tem sido palco das mais variadas investidas, não somente de ordem arquitetônica e urbanística, mas também de toda sorte de intervenções econômicas, sociais, culturais e políticas. Tal cenário reflete e refrata uma análise demográfica prospectiva que sinaliza o crescimento demográfico da população, que deverá duplicar até $2050^{2}$, e a precariedade das condições de vida nas grandes metrópoles. Na emergência de um novo paradigma que abarque as contradições próprias do ambiente urbano, sociólogos como Fortuna (2002) apontam para a (inevitável) necessidade de se construir não apenas mais cidades, mas também melhores cidades. A questão central que se apresenta é: seremos capazes de construir a cidade que imaginamos?

Abordamos, neste artigo, o consumo da cidade a partir da produção de sentidos e dos discursos presentes em projetos de reurbanização da região central da cidade de São Paulo. Definimos o consumo da e não na cidade, o que se justifica pelo fato de buscarmos uma análise a partir da produção de sentidos e de discursos. Assim, abordamos não o que as palavras dizem, mas como elas dizem, contextualizadas em projetos de reurbanização que encerram modos de conceber o espaço urbano e o seu consumo. Dedicamo-nos à análise de projetos com proposta de intervenção na região central - nas dimensões verbal e/ou não verbal - buscando os efeitos de sentido a partir de um contexto no qual atuam a história, o social e a ideologia.

A Análise de Discurso, como seu próprio nome indica, não trata da língua, não trata da gramática, embora todas essas coisas lhe interessem. Ela trata do discurso. E a palavra discurso, etimologicamente, tem em si a ideia de curso, de percurso, de correr por, de movimento. 0 discurso é assim palavra em movimento, prática de linguagem: com o estudo do discurso observa-se o homem falando (ORLANDI, 2009, p. 15).

O centro de São Paulo nos permite olhar a cidade em uma perspectiva crítica acerca dos discursos institucionalizados sobre esta região. Lugar de

\footnotetext{
2 Centro Regional de Informação das Nações Unidas. No fim do ano, metade da população regional viverá em cidades. Disponível em: <https://bit.ly/2SaCvDD>. Acesso em 20.08.2019.
}

Dossiê Espaço Urbano e Imaginação Cultural - https://revistaecopos.eco.ufrj.br/

ISSN 2175-8689 - v. 22, n. 3, 2019

DOI: 10.29146/eco-pos.v22i3.27414 
diálogos, debates e embates, o centro nos proporciona uma investigação atual sobre a forma e a função que a cidade adquire, próprias do seu espaço-tempo histórico. A imagem da cidade global, criativa, inteligente e sustentável emerge como característica aspiracional e inspiracional para os diversos projetos arquitetônicos e urbanísticos propostos, os quais pouco abordam seu contexto social e a sua materialidade, posto que alicerçam seus argumentos em ideias associadas ao passado glorioso e glamouroso da cidade de São Paulo, ao investimento na produção imobiliária e ao futuro, que se apresenta como a realidade imaginada e planejada a ser construída.

Definimos como questão a ser debatida a produção de sentidos sobre a cidade de São Paulo, notadamente aquela promovida no âmbito de projetos de reurbanização e as concepções de cidade que justificam a intervenção no centro desta metrópole brasileira. Poder público, especialistas e mercado estão envolvidos no desenvolvimento desse projeto que visa a reurbanização de uma área que é alvo de muita especulação, pois o centro é locus singular para se pensar as dinâmicas da cidade. Nesta direção, temos como objetivo analisar a produção de sentidos sobre a cidade de São Paulo, na perspectiva da comunicação e do consumo, a partir dos discursos publicizados nos projetos de reurbanização apresentados em períodos distintos, por atores distintos.

Para tanto, o corpus a ser analisado são três propostas de intervenção na região central da cidade de São Paulo: Projeto Nova Luz, de 2011 (Prefeitura de SP - gestão Serra/Kassab); Projeto Centro Novo, de 2017 (Prefeitura de SP - gestão Dória); e Projeto Campos Elísios Vivo, de 2018 (Coletivo Mundaréu da Luz). Destacamos dois momentos que consideramos cruciais no contexto político, econômico e sociocultural no qual os referidos projetos são publicizados: (1) o novo projeto de requalificação do Centro de São Paulo (jul. 2018) e (2) e o anúncio da extinção do Ministério das Cidades (jan. 2019). Tomamos como base, além dos estudos de comunicação e consumo, as reflexões sobre o direito à cidade de Lefebvre e a morfologia do espaço habitado de Milton Santos.

Dossiê Espaço Urbano e Imaginação Cultural - https://revistaecopos.eco.ufrj.br/

ISSN 2175-8689 - v. 22, n. 3, 2019

DOI: $10.29146 /$ eco-pos.v22i3.27414 
Se, conforme explica Lefebvre (2001), não é possível modificar as muralhas sem modificar o homem, a cidade apresenta-se como uma mediação entre mediações: o que anularia a distinção entre a cidade - realidade presente, imediata, dado prático sensível, arquitetônico - e o urbano - realidade social composta de relações a serem concebidas, construídas ou reconstruídas pelo pensamento (LEFEBVRE, 2001, p. 54). É justamente neste contexto urbano que as lutas das facções, de grupos e de classes reforçam o sentimento de pertencer. Logo, o consumo da cidade e as lógicas do habitar encontram-se inseridos em diferentes reflexões urbanísticas, isto é, um racionalismo operacional sobre a cidade. Diante desse cenário, nosso objetivo recai sobre dois aspectos: (1) identificar, nos discursos institucionalizados, as características projetadas para a cidade; e (2) estabelecer uma relação entre esses discursos e seus contextos, com a finalidade de olhar a cidade, considerando seus espaços construídos e seus espaços vividos, bem como refletir sobre suas implicações. 0 discurso institucionalizado sobre o tema refere-se ao discurso governamental e ao discurso técnico (arquitetos, urbanistas, juristas e movimentos da sociedade civil organizada).

Esperamos com este trabalho contribuir para os estudos sobre os sentidos da cidade a partir de uma perspectiva comunicacional, que pretende ir além das especificidades do direito à habitação e de condições de vida digna no espaço urbano. Almejamos, ainda, a promoção de um novo diálogo (que inclua o debate) sobre o ideal de cidade que construímos com base em diferentes reflexões urbanísticas: o urbanismo dos homens de boa vontade (arquitetos); o urbanismo dos administradores (governo) e o urbanismo dos promotores de venda (mercado). No espaço a ser construído e projetado está o cidadão, o morador, o consumidor que o transforma em espaço vivido.

\section{Um projeto de cidade: o centro}

O que envolve um projeto de cidade? O geógrafo João Seixas (2015), ao tratar das projeções de Lisboa, evidenciando as utopias, as visões e as estratégias

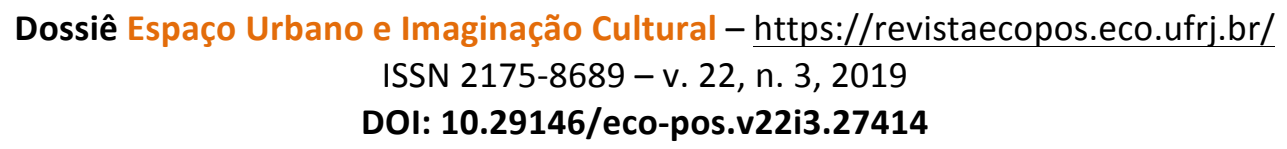


desenvolvidas para uma cidade (metrópole urbana) em movimento perpétuo, nos auxilia a pensar as razões, os desejos, as condições e os processos envolvidos na (re)produção/ (re)forma/ (re)qualificação do espaço urbano. Falar em projeto já implica falar em projeções; isto porque as projeções marcam de forma decisiva, visível e invisivelmente, em cada época, as ideias de futuro (SEIXAS, 2015, pg.12). Visões e projeções que se formam diante de anseios e pressões de várias ordens: afirmações políticas, contestações sociais, demandas privadas. Com isso em mente, tomamos os discursos, materializados nos textos de projetos de requalificação do centro da cidade de São Paulo, como nosso objeto privilegiado de análise.

Nos anos 1960, a região central da capital paulista era considerada nobre, muito valorizada e concorrida na cidade. A partir dos anos 1980, quando a degradação começou a prevalecer, já foram inúmeras as tentativas de autoridades do governo e de voluntários da sociedade civil de colocar em prática projetos para sua revitalização. Começou com Jânio Quadros $(1986-1988)^{3}$, com a proposta de revitalizar a região da ponte Santa Ifigênia. Nas gestões de José Serra (2005-2006) e Gilberto Kassab (2006-2012) foi arquitetado o plano Nova Luz, que envolvia basicamente a região conhecida como a Cracolândia, que engloba uma grande parte do centro, em que se incluem as Avenidas Duque de Caxias, Ipiranga, Rio Branco, Cásper Líbero e Rua Mauá. Nesse período, foram feitas reformas importantes, como a restauração da Pinacoteca, a criação da Sala São Paulo dentro da estação Júlio Prestes e o Museu da Língua Portuguesa, ligado à estação da Luz. Na gestão de Fernando Haddad (2013-2016) este plano não avançou, mas a prefeitura iniciou estudo para a revitalização do Vale do Anhangabaú, com projeto recebido do escritório do arquiteto e urbanista dinamarquês Jan Gehl, famoso pelo seu livro Cidade para pessoas 4 .

Recentemente, na gestão do prefeito João Dória (2017-2018), o debate sobre a revitalização do centro volta à tona. 0 principal argumento, que se

3 GOUSSINSKY, Eugenio. R7 São Paulo. Planos de revitalização do centro empacam gestão após gestão. 01.05.2018. Disponível em:<https://bit.ly/2Ku4nzG >. Acesso em 20.08.2019.

4 Gehl. Making Cities for People. Disponível em: <https://gehlpeople.com>. Acesso em 20.08.2019.

Dossiê Espaço Urbano e Imaginação Cultural - https://revistaecopos.eco.ufrj.br/

ISSN 2175-8689 - v. 22, n. 3, 2019

DOI: $10.29146 /$ eco-pos.v22i3.27414 
encontra referido nos projetos anteriores e que justifica as ações da Prefeitura na região, é a eliminação da chamada Cracolândia, denominação que se tornou popular para esta área do centro de São Paulo onde, a partir dos anos 2000, desenvolveu-se intenso tráfico de drogas, além da prática da prostituição, o que vigora na região desde as últimas décadas do século XX. Este cenário propiciou uma intervenção policial de grande envergadura nesta área, ao mesmo tempo em que a prefeitura canalizava seus esforços para abrir espaço à parceria públicoprivada (PPP) destinada à produção de $3.863^{5}$ unidades habitacionais.

A crítica a este e demais projetos de revitalização do centro de São Paulo reside no modo como é justificada a arbitrariedade das demolições, que de forma alguma representam alternativa aos moradores da região, alinhando-se mais a uma política de higienização do que uma política de interesse social. Para os especialistas do LabCidade $^{6}$ (Laboratório espaço público e direito à cidade), que fizeram um mapeamento ${ }^{7}$ dos processos urbanísticos em curso no centro de São Paulo, a maioria dos projetos impostos pelo Estado para o centro (e, principalmente para a região da Luz) tem ou teve uma visão preconcebida: a ideia inquestionável de que se trata de um espaço vazio, sem vida, o que leva ao pressuposto da necessidade de revitalização, ou seja, de um projeto que nega a vida e a cidade que existe para colocar no seu lugar empreendimentos imobiliários, realizados por grandes incorporadoras, que supostamente trariam de volta a classe média e a elite.

Por um lado, o governo do Estado de São Paulo, em parceria com a prefeitura, articula a construção, na região, de conjuntos habitacionais e de um

\footnotetext{
5 MARTIN, Isabel.; BRITO, Gisele; MENDONÇA, Pedro; LIMA, Pedro e ROLNIK, Raquel. Le Monde Diplomatique Brasil. Região da Luz em disputa: mapeamento dos processos em curso. 13.06.2017. Disponível em: $<$ https://bit.ly/2KT7pP8>. Acesso 20.08.2019.

${ }^{6}$ LabCidade (Laboratório espaço público e direito à cidade). Trata-se de um laboratório de pesquisa e extensão da Faculdade de Arquitetura e Urbanismo da Universidade de São Paulo que tem como foco de atuação o acompanhamento crítico das políticas urbanas e habitacionais, particularmente em São Paulo e em outras regiões metropolitanas brasileiras. Site. www.labcidade.fau.usp.br. Acesso em 20.08.2019.

70 mapeamento urbanístico feito pelo LaBCidade com o título Região da Luz em disputa: mapeamento dos processos em curso (08.06.2017) está disponível para consulta em <https://drive.google.com/file/d/0Bn77aCjawPIenNNRGtKcFc4Q2c/view >. Acesso em 20.08.2019.
}

Dossiê Espaço Urbano e Imaginação Cultural - https://revistaecopos.eco.ufrj.br/

ISSN 2175-8689 - v. 22, n. 3, 2019

DOI: $10.29146 /$ eco-pos.v22i3.27414 
hospital, em parceria-pública privada (PPP). Por outro lado, um grupo de moradores e comerciantes, acusam o poder público de descaso e truculência ${ }^{8}$.

Segundo a professora e urbanista Simone Gatti (2018), até o início do século XXI as tentativas de transformação urbana no centro de São Paulo estavam pautadas nos projetos culturais e na valorização do espaço público. Os governos municipais e estaduais investiram massivamente no restauro do patrimônio histórico e cultural e na revitalização de espaços públicos significativos. Apesar do êxito de alguns projetos culturais, segundo a urbanista pouca coisa mudou; grande parte das áreas que receberam tais investimentos não se transformaram. Hoje, o tema é outro: a preocupação de interesse social com equipamentos públicos e melhoria urbanística toma lugar face ao grande vácuo das intervenções das gestões municipais sobre a região central.

Desse vácuo de preocupação com a população vulnerável também emergem as iniciativas coletivas e populares: é o caso do Fórum Mundaréu da Luz ${ }^{9}$, coletivo que atua na região desde 2017 e que encabeça a formulação de uma proposta de planejamento urbanístico como uma resposta às ações governamentais. Intitulado Campos Elíseos Vivo ${ }^{10}$, o projeto é resultado de uma série de debates realizados junto à população e elaborado com o apoio de diversas instituições ${ }^{11} \mathrm{e}$ profissionais de diferentes áreas, como urbanismo, saúde, direito, cultura e serviço social.

\footnotetext{
8

${ }^{9}$ Coletivo Mundaréu da Luz. Disponível em: <https://mundareudaluz.org/camposeliseosvivo/>. Acesso em 20.08.2019.

10 Campos Elíseos Vivo. Disponível em:

$<$ https://mundareudaluz.files.wordpress.com/2018/04/completo_caderno-plano-alternativo-luz-r09-201804-10_web1.pdf> Acesso em 20.08.2019.

11 Algumas instituições que contam na proposta de apoio para o Mundaréu da Luz: (1) Centro Gaspar Garcia de Direitos Humanos; (2) Defensoria Pública de São Paulo, núcleos especializados: Promoção e Defesa dos Direitos das Mulheres (Nudem), Habitação e Urbanismo (Nehaburb), Cidadania e Direitos Humanos (NECDH), Direitos do Idoso e da Pessoa com Deficiência (Nediped); (3) IAB-SP - Instituto de Arquitetos do Brasil/São Paulo; (4) LabCidade - Laboratório Espaço Público e Direito à Cidade/FAUUSP; (5) LabJUTA - Laboratório Justiça Territorial/UFABC etc.
}

Dossiê Espaço Urbano e Imaginação Cultural - https://revistaecopos.eco.ufrj.br/

ISSN 2175-8689 - v. 22, n. 3, 2019

DOI: $10.29146 /$ eco-pos.v22i3.27414 
O debate ganhou mais elementos com a divulgação na mídia do Projeto Centro Novo ${ }^{12}$, um plano de intervenção para a região central de São Paulo elaborado pelo arquiteto Jaime Lerner, contratado pelo SECOVI (sindicato do mercado imobiliário) e doado ao prefeito João Dória. Segundo divulgação na imprensa, o projeto propõe a requalificação do centro de São Paulo, a partir de intervenções que tornem a região mais amigável e atraente para a população, reforçando a vocação do centro como um polo de economia criativa ${ }^{13}$.

Os termos que caracterizam/qualificam esses projetos - reurbanização, revitalização e requalificação - são índices de uma invisibilização planejada de algo que é representado como negativo - desurbanizado, desvitalizado e desqualificado - para dar lugar a algo novo e melhor. 0 cenário se apresenta como tela em branco, pronta para ser preenchida; contudo, conforme aponta Raquel Rolnik (2017), a região do centro é repleta de pré-existências que precisam ser levadas em consideração, tal qual os bens tombados e suas áreas envoltórias. 0 que está em jogo, portanto, é como e para quem estas iniciativas são dirigidas. Em uma tentativa de colocarmos o debate em perspectiva, apresentaremos a seguir um quadro comparativo dos projetos apresentados - Serra-Kassab, Mundaréu da Luz e João Dória -, considerando suas implicações tanto para a produção do espaço construído quanto para a reprodução do espaço vivido.

\section{Uma construção viva: o urbano}

A cidade sempre foi o epicentro de aspirações e inspirações humanas. Por isso, pensar os discursos e sua produção de sentido sobre a cidade, para além de um artefato que se molda por desenho e por planejamentos tendencialmente universais e generalistas, implica vê-la como um organismo vivo que requer várias

\footnotetext{
12 Nota. Secretaria Municipal de Comunicação. Prefeitura recebe o projeto Centro Novo. 26.09.2017. Disponível em: $<$ https://bit.ly/2Nk7VGU $>$. Acesso em 20.08.2019.

${ }^{13}$ A vida no centro. Site. Caderno Cidades. Projeto Centro Novo, de Jaime Lerner, reforça a vocação do centro para a economia criativa. 26.09.2017. Disponível em: < https://bit.ly/2TYfCFd $>$. Acesso em 20.08.2019.
}

Dossiê Espaço Urbano e Imaginação Cultural - https://revistaecopos.eco.ufrj.br/

ISSN 2175-8689 - v. 22, n. 3, 2019

DOI: $10.29146 /$ eco-pos.v22i3.27414 
formas de interação ativa para a sua reinvenção (SEIXAS, 2015). É no uso do espaço que se organizam comportamentos, trajetos e percursos que o cidadão realiza cotidianamente e que marcam os modos de apropriação dos lugares da cidade. No entanto, esses lugares são constantemente redefinidos pela morfologia urbana, seja através das políticas públicas, seja através de estratégias imobiliárias que condicionam o uso do espaço da cidade a sua condição de mercadoria. Conforme destaca Carlos (2007), ao privilegiar-se determinadas áreas da cidade abrindo avenidas, destruindo bairros, fechando ruas, impedindo usos e determinando outros -, implode-se a sociabilidade, desloca-se habitantes, influencia-se a valorização dos bairros e acentua-se a desigualdade (CARLOS, 2007, pg. 15). O discurso, portanto, torna-se elemento central na conformação do consumo da e na cidade. Para compreender as lógicas de produção desses discursos, ou seja, os mecanismos que engendram a produção e a circulação de sentidos no contexto de reformas urbanas, dedicamo-nos a analisar como a cidade é concebida em cada um dos projetos urbanísticos mencionados.

Numa primeira etapa de tratamento do material empírico, formulamos cinco critérios para a observação do corpus a partir dos sumários dos respectivos projetos. Estes sumários foram utilizados como guias para a compreensão dos sentidos atribuídos ao espaço urbano - e, consequentemente, à cidade - no que tange às justificativas para toda sorte de intervenções.

Ao primeiro critério denominamos destaque, objetivando identificar o que é visibilizado no discurso; ao segundo, a regularidade, que aponta para uma unicidade do discurso; ao terceiro, a projeção, entendida como experiências e expectativas presentes no discurso; ao quarto, quem fala, ou seja, a voz crível e legitimada do discurso; por fim, para quem fala, isto é, os discursos mobilizados para produção de sentidos para grupos de interesse. Abaixo, apresentamos um quadro sintético elaborado a partir desses critérios:

Quadro 1. Sumários: Projeto Urbanístico Centro SP.

Dossiê Espaço Urbano e Imaginação Cultural - https://revistaecopos.eco.ufrj.br/

ISSN 2175-8689 - v. 22, n. 3, 2019

DOI: 10.29146/eco-pos.v22i3.27414 


\begin{tabular}{|l|l|l|l|}
\hline $\begin{array}{l}\text { Critérios de } \\
\text { observação do } \\
\text { corpus }\end{array}$ & $\begin{array}{l}\text { Projeto Nova Luz } \\
\text { (Serra-Kassab) }\end{array}$ & $\begin{array}{l}\text { Campos Elíseos Vivo } \\
\text { (Fórum Aberto } \\
\text { Mundaréu da Luz) }\end{array}$ & $\begin{array}{l}\text { Centro Novo (João } \\
\text { Dória) }\end{array}$ \\
\hline DESTAQUE & Hoje e 2025 & $\begin{array}{l}\text { Urbanístico e social; } \\
\text { comunidade }\end{array}$ & Visão \\
\hline REGULARIDADE & $\begin{array}{l}\text { Estratégia; Diretrizes; } \\
\text { Tipologia; Parâmetro. }\end{array}$ & $\begin{array}{l}\text { Imersão; } \\
\text { Potencialidades; } \\
\text { Moradores; Moradas; } \\
\text { Fluxos; Viabilidade. }\end{array}$ & $\begin{array}{l}\text { Centro; Cosmopolita; } \\
\text { Vibrante; } \text { Mobilidade; } \\
\text { Promoção; Divulgação. }\end{array}$ \\
\hline PROJEÇÃO & $\begin{array}{l}\text { Futuro: Nova Luz: Hoje } \\
\text { e 2025 }\end{array}$ & $\begin{array}{l}\text { Presente: Campos } \\
\text { Elíseos Vivo }\end{array}$ & $\begin{array}{l}\text { Passado-Futuro: Uma } \\
\text { (nova) visão para o } \\
\text { Centro. }\end{array}$ \\
\hline QUEM FALA & Canopus Holding S.A. & $\begin{array}{l}\text { Coletivo Mundaréu da } \\
\text { Luz }\end{array}$ & $\begin{array}{l}\text { Jaime Lerner } \\
\text { Arquitetos Associados }\end{array}$ \\
\hline PARA QUEM FALA & Prefeitura SP & Comunidade & Mercado \\
\hline
\end{tabular}

Fonte: Elaborado pela autora, a partir dos documentos (projetos analisados) tornados públicos e disponibilizados online.

O projeto Nova Luz traz como elemento de fundo a projeção de futuro: a revitalização urbana do centro está assentada em sua imagem projetada para 2025. A partir daí, toda a estratégia de planejamento vai ao encontro desse cenário. A argumentação é construída com base em dados e estatísticas recolhidas, em sua grande maioria, da própria prefeitura e do governo federal. Embora o documento formule um cenário com elevado potencial de requalificação (social, econômico e ambiental), devido à sua localização estratégia e larga dotação de infraestrutura, não aponta qualquer indício de uma experiência com o lugar. Isso pode ser observado no texto que apresenta a metodologia: "houve uma ampla análise e pesquisa para determinar as principais restrições e oportunidades encontradas na área, levando em conta estudos urbanos já realizados". Na sequência, "dá-se especial ênfase ao caráter arquitetônico, à distribuição do uso do solo, às áreas livres e públicas e avaliação das principais rotas de circulação (...)" (PUE Consolidado, 2011, p.2.1). Com este cenário, a problemática urbana se realiza 
no plano teórico, enquanto a produção da cidade e do urbano se coloca no plano da prática sócio-espacial, evidenciando a vida na cidade (CARLOS, 2007).

Já o projeto Campos Elíseos Vivo traz explícito o sentido coletivo no título "um projeto urbanístico e social elaborado com a comunidade". Dividido em três partes, toma como ponto de partida a imersão no território, para depois apresentar a proposta que aponta as potencialidades do espaço (físico) e as modalidades de atendimento (humano) em três eixos: (1) morar e trabalhar; (2) amar e cuidar e (3) estar na rua e conviver; e, por fim, as estratégias para sua viabilidade econômica e financeira. Apesar de uma configuração menor em termos de divisões e subdivisões do projeto, em nada perde em termos de conteúdo e profundidade das análises, conforme assinalado no documento:

\footnotetext{
o projeto contou com a participação de companhias e coletivos culturais, organizações que atuam no campo da saúde mental, universidades (por meio de laboratórios e escritórios-modelo de arquitetura e urbanismo, história social e psicologia), ONGs com atuação em políticas urbanas e de assistência social, dentre outros grupos" (Campos Elíseos Vivo, 2017, p. 08).
}

Este projeto reforça uma abordagem que concebe o ser humano não mais como indivíduo isolado, mas como um ser social por excelência, e esse dinamismo encontra-se na transformação qualitativa e quantitativa do espaço habitado (SANTOS, 2014). Encontramos aqui a problemática urbana na oposição entre o valor de uso (a cidade e a vida urbana, o tempo urbano) e o valor de troca (os espaços comprados e vendidos, o consumo dos produtos, dos bens, dos lugares e dos signos) (LEFEBVRE, 2001).

O tensionamento valor-uso e valor-troca fica evidente no projeto Centro Novo, no qual o valor estético (LIPOVETSKY; SERROY, 2015) permeia as imagens, a forma e os relatos inscritos no documento. Intitulado "Uma nova visão para o Centro de São Paulo", o projeto concentra-se em três pontos: o primeiro trata de conceituar o espaço (Centro Cosmopolita, Multicultural e Vibrante) e definir objetivos (promover, melhorar, valorizar, capitalizar, ressaltar, aumentar, desenvolver); na sequência, identifica os espaços denominados como "âncoras e

Dossiê Espaço Urbano e Imaginação Cultural - https://revistaecopos.eco.ufrj.br/

ISSN 2175-8689-v. 22, n. 3, 2019

DOI: 10.29146/eco-pos.v22i3.27414 
tesouros da área central"; e, por fim, as ideias-força, isto é, as mudanças que resultam em um novo cenário urbano (os boulevares centrais, os portais de São Paulo, o circular central, o polo de economia criativa e as acupunturas urbanas). Essa nova visão do centro de São Paulo é ilustrada no projeto como resultado de uma memória afetiva:

\begin{abstract}
(...) é uma oportunidade de recordar ao paulistano memórias afetivas atreladas a esse espaço nobre da cidade, que associações negativas ao longo do tempo fizeram esmaecer, e reapresentá-lo às novas gerações. Ressaltar a beleza, resgatar o lustro, reparar o apreço, restaurar a alegria e a autoestima desse cenário privilegiado de encontro. É um trabalho de captura da imaginação e do sonho, da reabilitação da imagem e da percepção, de uma reivindicação desse centro para o século XXI" (Centro Novo, 2017, p. 02).
\end{abstract}

Neste sentido, o aspecto mais significativo da cidade reside na funcionalidade de sua magnitude, que se faz sentir para além de seus limites físicos (SIMMEL, 1997).

Se o projeto Nova Luz aponta para o futuro, o Centro Novo busca suas referências no passado. Entre um tempo e outro - aquele que ainda não é e aquele que já foi -, o presente se materializa nas experiências cotidianas, na cidade enquanto ponto de partida e de chegada. Neste sentido, o projeto Campos Elíseos Vivo emerge como concretude de uma realidade pautada no presente. Essa análise é significativa, pois traz diferentes discursos sobre a cidade e estabelece uma relação com seus contextos.

Considerando os sentidos que emergem no sumário de cada projeto - sejam os do governo municipal e o de grupos não governamentais, desenvolvemos a seguir reflexões sobre o direito à cidade, as culturas do consumo e suas lógicas e ordenamentos para a vida urbana.

\title{
4. Diálogos, embates e debates: o direito à cidade
}

Freitag (2012), ao traçar as teorias da cidade, faz um percurso sobre as diversas correntes de estudo da questão urbana: a escola alemã de sociologia urbana e o privilégio da história e da cultura; os pensadores franceses enfatizando

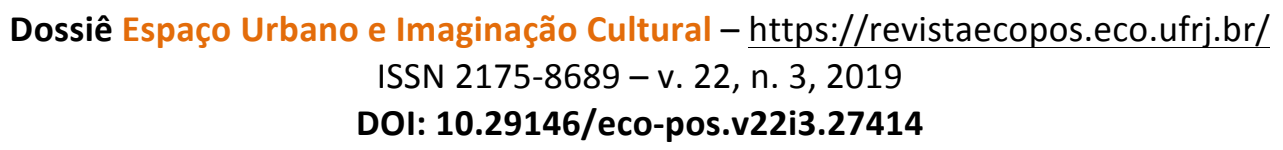


a dimensão de racionalidade e utopia; os autores da escola inglesa destacada por seu pragmatismo e utilitarismo; e, finalmente, os americanos que, embora tragam grande afinidade com os ingleses, estabelecem uma diferença significativa entre a concepção das cidades modernas e sua prática com a inovação tecnológica (o automóvel, as autoestradas, a eletricidade, ou seja, o que propiciou, em linhas gerais, a verticalização das cidades).

Todas as mencionadas escolas tiveram, em diferentes medidas, repercussão no Brasil, mas o modelo americano, após o período de modernização e urbanização iniciado nos anos 1950, alicerça em grande parte a concepção de cidade brasileira com a cultura do shopping center, do automóvel, do condomínio e de grandes empreendimentos que se destinam a grupos sociais de alto poder aquisitivo. 0 reverso da medalha são favelas, invasões e ocupações clandestinas do espaço sobre os quais o Estado já perdeu o controle (FREITAG, 2012, p. 132). Neste sentido, não há teoria urbana que possibilite enquadrar adequadamente as questões básicas para uma política habitacional que contemple a complexidade da sociedade brasileira (id, p. 133). Por conseguinte, os espaços que surgem espontaneamente, sem a intervenção planejadora do arquiteto e do urbanista, refletem uma lógica que não deve ser ignorada ou menosprezada, como percebemos nos projetos sobre o centro de São Paulo. 0 único projeto, dentre os que analisamos, que apresenta uma proposta inclusiva neste sentido é o Coletivo Mundaréu da Luz, e o faz a partir de um esforço em enfrentar, conforme publicado em seu documento, "as questões complexas presentes hoje nesse território, que vão desde precariedades habitacionais e vulnerabilidades sociais à presença de um enorme patrimônio cultural material e imaterial, em constante construção e renovação". Os demais projetos tratam das "dinâmicas socioculturais" atreladas ao espaço como "constituindo uma localização desafiadora" (Projeto Nova Luz). Ou, ainda, uma visão do centro como um "repositório de potencialidades que estão latentes no coração da maior metrópole do hemisfério sul” (Centro Novo).

Lefebvre (2001), ao fazer um balanço da sociedade pós-industrial capitalista e a expansão urbana, analisa como uma urbanização muitas vezes

Dossiê Espaço Urbano e Imaginação Cultural - https://revistaecopos.eco.ufrj.br/

ISSN 2175-8689 - v. 22, n. 3, 2019

DOI: $10.29146 /$ eco-pos.v22i3.27414 
idealizada como forma de progresso nem sempre alcança êxito devido aos muitos grupos de interesses a ela associados. Para o autor, a crise da cidade emerge por meio da imbricada situação do conceito de cidade, que se compõe de fatos, de representações e de imagens. 0 núcleo urbano, ainda que esteja rachado, consegue se manter, ou seja, não desaparece (LEFEBVRE, 2001, p. 21). Isto explica a imagem do centro de São Paulo que suscita as mais diversas qualificações sem com isso abarcar a realidade cotidiana. É sobre essa cotidianidade que os projetos aqui apresentados foram pautados e respondem, em sua operacionalidade, a uma lógica de produção discursiva distinta daquela das interações e da vida vivida no cotidiano pela população:

1) o projeto Nova Luz prende-se a um racionalismo operatório, que se manifesta nas práticas do capitalismo financeiro, notadamente a reprodução do espaço urbano por meio da produção imobiliária;

2) o projeto Campos Elíseos Vivo privilegia a sociologia e a antropologia do espaço, levando em conta conhecer de forma aprofundada não somente os aspectos físicos, mas, principalmente, os aspectos humanos - socioculturais e afetivos;

3) o projeto Centro Novo coloca o urbanismo como promotor privilegiado de uma marca-lugar - place branding -, por meio da qual é apresentado um novo modo de viver a cidade, uma vida cotidiana miraculosa e maravilhosamente transformada.

A partir destas concepções do espaço urbano e, por consequente, de um projeto de cidade determinado, podemos antever como se constrói o contrato de comunicação e o interlocutor implicado por meio da atribuição de sentidos ao território a ser reformado: no caso do projeto Nova Luz, a tecnicidade e a gestão administrativa do espaço urbano estão presentes no texto, de modo a criar uma interlocução com os gestores públicos que se mostram mais afeitos a uma narrativa objetiva e funcional; já o projeto Campos Elíseos Vivo privilegia a interlocução entre os diversos agentes que, de alguma forma, fazem parte do tecido urbano e suas institucionalidades; por fim, o projeto Centro Novo, privilegia

Dossiê Espaço Urbano e Imaginação Cultural - https://revistaecopos.eco.ufrj.br/

ISSN 2175-8689 - v. 22, n. 3, 2019

DOI: $10.29146 /$ eco-pos.v22i3.27414 
a estetização da cidade, e, ao trazer imagens e percepções de modo fragmentado do espaço urbano, confunde-se com campanhas publicitárias de divulgação turística, que evidenciam uma compreensão mercadológica do espaço urbano.

Numa outra perspectiva de análise do corpus, distinta daquela do contrato de comunicação instaurado a partir dos sentidos atribuídos à cidade, consideramos as políticas que são próprias do sistema de governo, que suscitam grandes desafios. Algumas instâncias, como é o caso do Ministério das Cidades, poderiam auxiliar como mediador entre os diversos partícipes da construção da cidade e do urbano. Embora os projetos se detenham na instância municipal, o estado e o governo federal deveriam participar ativamente neste processo, pois, conforme argumenta o pesquisador Eduardo Marques, do Centro de Estudos da Metrópole, a criação do Ministério das Cidades (2003) representou uma volta do governo federal à produção de políticas urbanas no Brasil, da qual estivera ausente desde a extinção do Banco Nacional de Habitação (o BNH), em 198614. Com o ministério, o país passou a ter um Plano Nacional de Habitação, um Plano Nacional de Saneamento Básico, um Plano de Mobilidade Urbana e, ainda, um Conselho Nacional das Cidades, instrumento de participação democrática na Política Nacional de Desenvolvimento Urbano, do qual participaram o setor produtivo, movimentos populares, setor público e acadêmicos.

Apesar desses avanços, os programas e ações do ministério viveram um declínio nos últimos dois governos (Dilma Rousseff, 2011-2016 e Temer, 20162018) e, finalmente, no mandato do atual presidente da república Jair Bolsonaro (2019), foi extinto e incorporado ao Ministério da Integração Nacional ${ }^{15}$. A justificativa para essa decisão foi a questão do repasse federal diretamente aos seus governos e municípios. No entanto, especialistas alegam que tal medida pode causar constrangimentos ou desvios, uma vez que não está previsto nenhum tipo

\footnotetext{
14 LIMA, Juliana Domingos. Nexo Jornal. Qual a importância do Ministério das Cidade para a política urbana no Brasil. 04.11.2018. Disponível em: <https://bit.ly/2SWHBVk>. Acesso em 20.08.2019.

${ }^{15}$ Agencia Brasil. EBC. Política. Veja quem são os ministros de Jair Bolsonaro. 01.01.2019. Disponível em: $<$ https://bit.ly/2VlUSYV>. Acesso em 20.08.2019.
}

Dossiê Espaço Urbano e Imaginação Cultural - https://revistaecopos.eco.ufrj.br/

ISSN 2175-8689 - v. 22, n. 3, 2019

DOI: $10.29146 /$ eco-pos.v22i3.27414 
de controle ou fiscalização do repasse. Integrantes da Frente Nacional de Prefeitos (FNP) ${ }^{16}$ e o presidente do Conselho de Arquitetura e Urbanismo do Brasil, Luciano Guimarães ${ }^{17}$, manifestaram suas preocupações com esse novo cenário: é consenso que a pasta é importante para pensar a cidade de maneira integrada.

Para Carlos (2007), o direito à cidade no Brasil emergiu à ordem do dia com a criação do Ministério das Cidades e das Conferências sobre a cidade (CARLOS, 2007, p. 109). Com a extinção da pasta, há um profundo esvaziamento do debate quanto ao direito à cidade, que fica restrito às condições de habitação, suscitando soluções de curto prazo que não consideram as dinâmicas causadas pelo tensionamento presente no binômio uso-troca dos lugares da cidade. Neste sentido, a cidade aparece como elemento estranho à sociedade e reforça as contradições ali presentes, revelando um caminho de produção e reprodução do espaço urbano, seja físico-arquitetônico, seja humano, a partir de interesses e jogos de forças desiguais.

\section{Considerações Finais}

No dia 31 de outubro celebra-se o Dia Mundial das Cidades, e o ano de 2018 foi marcado pelo tema "Cidade Melhor, Vida Melhor"18. Essa nova agenda traz uma reflexão sobre a necessidade de se enfrentar os desafios ambientais e sociais do espaço urbano, por meio da melhor governança das infraestruturas e serviços disponíveis. Foi esta a data escolhida para a organização de uma petição online ${ }^{19}$ na tentativa de evitar a dissolução do Ministério das Cidades no Brasil. Embora não tenha surtido o efeito esperado, representou uma tentativa de resistência face

\footnotetext{
${ }^{16}$ Agência Brasil. EBC. Canal Política. Prefeitos reagem à extinção do Ministério das Cidades. 31.10.2018. Disponível em: <https://bit.ly/2zl98qu>. Acesso em 20.08.2019.

17 CAU/SC. Globo G1. Arquitetos e Urbanistas questionam possível extinção do Ministério das Cidades. 27.11.2018. Disponível em: <https://glo.bo/2NlhFAr>. Acesso em 20.08.2019.

18 Fórum Mundial das Cidades. Dia Mundial das Cidades. 31 de outubro. Disponível em:<https://bit.ly/2TVJceg>. Acesso em 20.08.2019.

19 Petição Online. Avaaz. Não ao fim do ministério das cidades. Disponível em: <https://bit.ly/2tuNuOj>. Acesso em 20.08.2019.
}

Dossiê Espaço Urbano e Imaginação Cultural - https://revistaecopos.eco.ufrj.br/

ISSN 2175-8689 - v. 22, n. 3, 2019

DOI: 10.29146/eco-pos.v22i3.27414 
aos ordenamentos institucionalizados. Tal fato nos ajuda a refletir sobre o espaço urbano, enquanto condição, meio e produção da ação humana.

Não podemos pensar a cidade separada da sociedade, dos fluxos comunicacionais e do seu tempo histórico. Desvendar os conteúdos mais profundos da urbanização através das contradições que estão postas nos discursos publicizados sobre a metrópole é o nosso desafio e nossa contribuição ao debate que articula comunicação, consumo e cidade.

A partir da análise dos projetos, apresentamos apontamentos que podem contribuir para o referido debate e promover frentes de atuação quanto às questões da cidade, quer no âmbito dos discursos que fazem circular sentidos, quer no âmbito das políticas públicas:

- Comunicação: o campo da comunicação, embora incorpore o discurso, é mais abrangente que este; portanto, ao analisarmos os discursos ampliamos as possibilidades de diálogo acerca das questões da cidade. Entender os sentidos produzidos nos discursos nos permite incluir as pessoas mais do que ampliar o alcance da mensagem.

- Consumo: há uma interdependência entre produção e consumo, de modo que, ao produzirmos discursos sobre a cidade, reiteramos ou transformamos nossa experiência do e no espaço urbano. Esse consumo não é mera satisfação de desejos; ele abarca elementos de sociabilidade que são importantes para tratar das dinâmicas locais e globais que capturam a cidade.

- Cidade: embora contemplem dimensões distintas, cidade e urbano são indissociáveis. A cidade e sua morfologia fundem-se com o urbano e sua metafísica. Em outras palavras, estamos imersos tanto em uma realidade presente, dado prático sensível, quanto em uma realidade social, construída e reconstruída pelo pensamento. Portanto, entender essa dinâmica nos 
auxilia a lidar com as contradições que cercam as investidas sobre a cidade, notadamente as cidades imaginadas e publicizadas na ordem dos discursos.

- Centro-periferia: as manifestações acerca do centro aparecem como oposição a periferia; no entanto, as articulações entre as diversas frações do espaço urbano extrapolam esta dicotomia e evidenciam novo contexto em rede, a qual tem papel fundamental na organização dos espaços e na interação entre as pessoas.

A partir da análise realizada, identificamos a urgência de se investigar a produção de sentidos sobre a cidade nas contemporâneas culturas do consumo, notadamente os discursos - midiáticos ou não - e suas convocações para produção e consumo da cidade na promoção e divulgação de uma marca cidade - caso do Projeto Novo Centro. Nesta perspectiva, desfiar os fios que tecem a produção de sentidos no tecido discursivo que envolve nossas vidas é tarefa que requer conceber comunicação e consumo como aspectos indissociáveis na análise crítica da cidade no Brasil.

Por fim, destacamos que o espaço construído - ou seja, projetado - tem sido privilegiado por ser a face visível da cidade e, neste contexto, a emergência de parcerias público-privadas (PPP) lança mão desta visibilidade como parâmetro para estabelecer seus lucros. Por sua vez, o espaço vivido, juntamente com as pessoas e suas existências, é negado por ser a face invisível da cidade e por distanciar-se da lógica que rege o mercado. Esta face invisível da cidade estabelece uma relação de consumo de outra ordem e desafia as instâncias públicas a uma governança socialmente eficaz.

\section{Referências bibliográficas}

CAMPOS ELÍSEOS VIVO. Disponível em: $<$ https://mundareudaluz.files.wordpress.com/2018/04/completo_caderno-planoalternativo-luz-r09-2018-04-10_web1.pdf> Acesso em 20.08.2019.

Dossiê Espaço Urbano e Imaginação Cultural - https://revistaecopos.eco.ufrj.br/

ISSN 2175-8689 - v. 22, n. 3, 2019

DOI: $10.29146 /$ eco-pos.v22i3.27414 
CARLOS, A. F. A. O espaço urbano: novos escritos sobre a cidade. São Paulo: FFLCH, 2007.

CENTRO NOVO. Uma visão para o centro de São Paulo. 2017. Disponível em: $<$ https://bit.ly/2T6ISMt>. Acesso em 20.08.2019.

FORTUNA, C. Culturas urbanas e espaços públicos: sobre as cidades e a emergência de um novo paradigma sociológico. Revista Critica de Ciências Sociais, n. 63, out.2002, p. 123-148.

FREITAG, Barbara. Teorias da cidade. Campinas, SP: Papirus, 2012.

GATTI, Simone. Le Monde Diplomatique Brasil. O habitar precário e invisível: conflitos e disputas da política habitacional no território da cracolândia. 04.07.2017. Disponível em: <https://bit.ly/2Ioptm4>. Acesso em 20.08.2019.

LEFEBVRE, Henri. $O$ direito à cidade. Tradução: Rubens Eduardo Frias. São Paulo: Centauro, 2001.

LIPOVETSKY, Gilles; SERROY, Jean. A estetização do mundo: viver na era do capitalismo artista. Tradução: Eduardo Brandão. 1a. ed. - São Paulo: Companhia das Letras, 2015.

ORLANDI, Eni Puccinelli. Análise de discurso: princípios \& procedimentos. Campinas: Pontes, 2009.

PUE. Projeto Urbanístico Específico. Subproduto 5.1 PUE Consolidado. 2011. Disponível em: < https://bit.ly/2Ej2Rzm> Acesso em 20.08.2019.

ROLNIK, Raquel. Blog. Projeto Centro Novo: mais do mesmo ou blefe midiático da prefeitura de SP? 02.10.2017. Disponível em: <https://bit.ly/2yTPvor >. Acesso em: 20.08.2019.

SANTOS, Milton. Metamorfose do espaço habitado: fundamentos teóricos e metodológicos da geografia. São Paulo: Editora da Universidade de São Paulo, 2014.

SEIXAS, João. A projeção de Lisboa: utopias, visões e estratégias para uma cidade em movimento perpétuo. Revista Rossio. Estudos de Lisboa. nr. 5, jun/2015, CML Câmara Municipal de Lisboa.

SIMMEL, Georg. A metrópole e a vida do espírito. In.: FORTUNA, C. (org.). Cidade, Cultura e Globalização: ensaios de sociologia. Oeiras: Celta Editora, 1997.

Dossiê Espaço Urbano e Imaginação Cultural - https://revistaecopos.eco.ufrj.br/

ISSN 2175-8689 - v. 22, n. 3, 2019

DOI: $10.29146 /$ eco-pos.v22i3.27414 